\title{
Optimisation of ground anchor head for non-destructive testing
}

Ana Ivanović MEng, PhD, CEng, MICE

School of Engineering, University of Aberdeen, Aberdeen, UK (corresponding author: a.ivanovic@abdn.ac.uk)

Alberto Monese MEng

School of Engineering, University of Aberdeen, Aberdeen, UK
Richard D. Neilson BSc, MSc, PhD, CEng, FIMechE

School of Engineering, University of Aberdeen, Aberdeen, UK

Ground anchorages and rock bolts are used widely in retaining walls, mines, dry docks, dams and prestressed structures to provide effective support for unstable rock strata. This paper offers a new design for ground anchor heads to maximise the quality of load estimation using the non-destructive ground anchorage integrity testing method. When using this method, the anchor head assembly needs to have a non-linear stiffness characteristic to permit changes in anchorage load to be detected. The initial estimate of the optimal stiffness characteristic is found using a lumped parameter dynamic model of the bolt assembly. Finite-element models of the proposed patented plate designs are then presented along with the corresponding load-displacement diagrams. The optimised bearing plate which was designed in this process was manufactured and tested experimentally, both statically and dynamically as part of a rock bolt assembly. The results from the experiments and the dynamic model are presented, and show good agreement. The resulting frequency shifts with a change of load prove the viability of building in the flexibility required to make non-destructive monitoring of load possible. The proposed design provides excellent load estimation.

\section{Notation}

A cross-sectional area

$a, b, c, d$ coefficients of polynomial cubic curve

E Young's modulus

$k_{\text {bolt }} \quad$ stiffness of the free length of the steel tendon

$k_{\mathrm{bp}} \quad$ stiffness of the bearing plate

$l_{\text {free }} \quad$ free length

$r \quad$ ratio between $k_{\mathrm{bp}}$ and $k_{\text {bolt }}$

$x \quad$ deflection

\section{Background}

\subsection{Introduction}

Structures such as mines, tunnels and retaining walls are often supported by ground anchorages and currently, millions of these are installed worldwide. Ground anchorages are capable of transmitting loads from structures to strong underlying rock or soil strata (BS 8081 (BSI, 1989); BS 7861: Part 1 (BSI, 1996)) to provide support. A number of different configurations exist depending on the application: whether in rock or soil, whether they are permanent or temporary, and whether they are active (prestressed) or passive (initially not stressed). Regardless of the type of anchorage, the common parts of any anchorage system are the protruding free and fixed anchor lengths, and an anchor head assembly through which the load is transmitted to the surrounding rock/soil mass (Figure 1(a)). The anchor head assembly consists of a stressing nut and a bearing plate in the case of a rock bolt, and a bearing plate and barrel with wedges in the case of a strand anchor. The main principle of applying the load to a bolt or cable/strand after installation is to stretch the tendon between the fixed anchorage length and the bearing plate, and thereby introduce compressive loads into the rock/soil surface that in turn provide stabilisation of the surrounding mass. Generally, monitoring of such anchorages is restricted to $5-10 \%$ of installations and is undertaken by means of pull out tests (Littlejohn and Mothersille, 2008), which are destructive, or by load cells which are too expensive to be used other than on a few high value assets. Consequently, the present practices of assessing anchorage quality and performance are limited, time consuming or destructive (Zou, 2004).

In the mining industry, rock bolts have been used increasingly in the last four decades and have become the primary support system (Hebblewhite and Lu, 2004; Whitaker, 2001). They have been proved to reduce the number of fatalities due to roof 


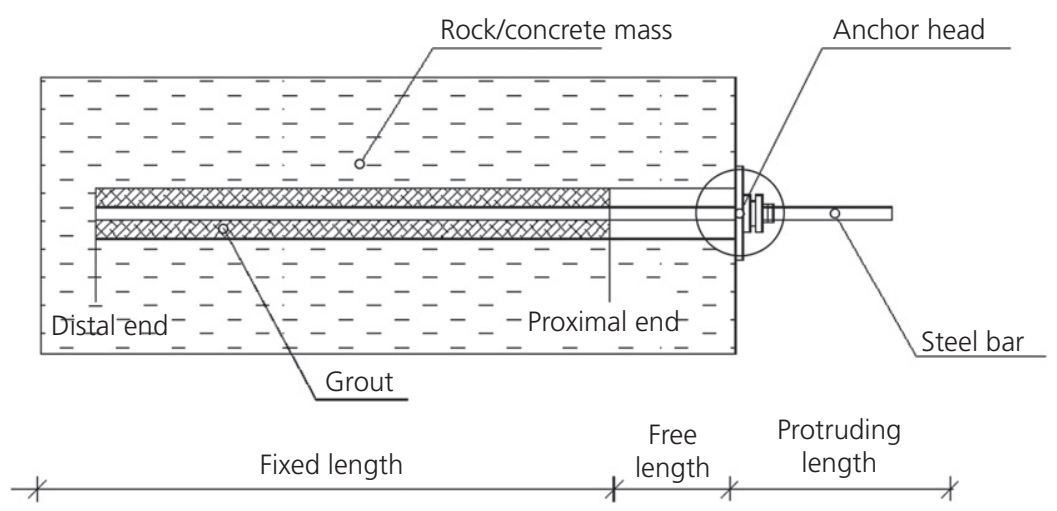

(a)

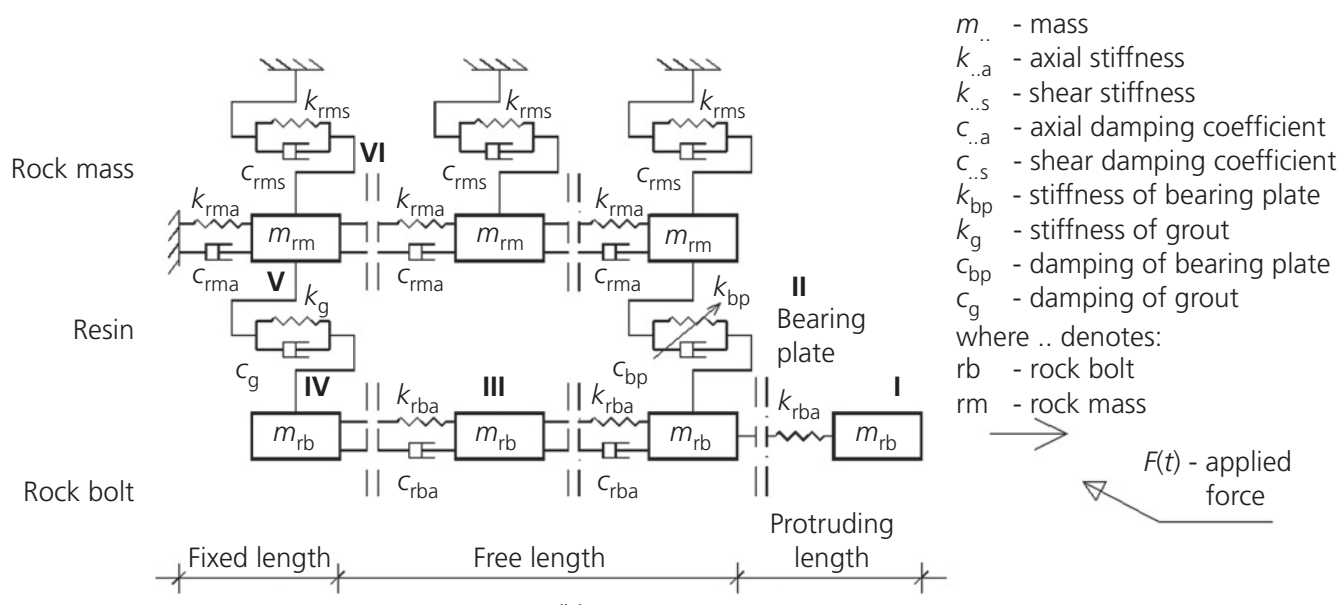

(b)

Figure 1. (a) Schematic diagram of a complete ground anchorage system and (b) lumped parameter model

fall accidents (Smelser et al., 1982). In a mine environment, the anchor head consists of the bearing plate and the nut for applying the desired load which in turn provides the roof support. The design of the bearing plates for rock bolts is, therefore, significant due to their role of providing this roof support. It was indicated by Cincilla and Tadolini (1986) and Tadolini and Ulrich (1986) that a well-designed bearing plate helps in resisting roof movement in the lower $0.6 \mathrm{~m}$ of the roof. Studies undertaken by Villaescusa et al. (2008) showed that the geometry - the thickness and shape of the bearing plate - has a significant influence in maintaining the load in the bolt especially after dynamic disruption such as blasting.

\subsection{Non-destructive testing (NDT)}

Due to the high number of anchorages and rock bolts installed throughout the years, an economical and effective method for monitoring their conditions is required to determine whether the installation has experienced any damage and has lost its reliability. A number of NDT methods have been developed. These are based mainly on ultrasonic methods (using piezoelectric transducers) (Thurner, 1979; Wittenberg and Ruppel, 2000), guided ultrasonic methods (Beard and Lowe, 2003), acoustic emission (Robert and Brachet-Rolland, 1982) or electromagnetic techniques (Bigby and Arthur, 2001). All the NDT methods have merits as well as disadvantages. The ultrasonicbased methods are generally only applicable to bolts and require the end of the bolt to be prepared to ensure good coupling between the transducer and the bolt, while the electromagnetic techniques have limited applicability that is dependent on the rock type. Acoustic emission, while good for identifying ongoing cracking, requires near continual monitoring and again good coupling to the bolt. None of these methods are suitable for providing an estimate of the load in the bolt and all the methods have very limited usage in the industry.

Research undertaken to address the need for a new method of anchorage assessment to provide estimation of the load in the 
anchorage led to the development of a NDT method, ground anchorage integrity testing (Granit) method. Granit operates by using a specially designed impact device (Neilson et al., 2007). The device applies an impulse load of small amplitude which effectively excites the natural frequencies of the system. The response of the anchorage is then measured by an accelerometer mounted on the device and recorded by a laptop computer. This response is then analysed in the frequency domain and compared with reference spectra obtained for different load levels from a datum anchorage of the same configuration (Figure 2).

The Granit system estimates load in an anchorage by relating the shift in frequency obtained to the different load levels. To determine which part of the anchorage system most influences the dynamic behaviour of the anchorage system and the shift in frequency, a lumped parameter model was used in the investigation. This model, developed previously by Ivanović et al. (2002) (Figure 1(b)), found that the stiffness of the anchorage head is the most influential part for the detection of load.

\subsection{Lumped parameter model}

The model consists of masses connected with springs and dash-pots, each representing a different part or interface within the anchorage system. The masses are calculated from the volume and density of each element, the axial stiffnesses, $k_{i}$, of the bar and the affected rock mass are calculated using Hooke's law, whereas the shear stiffnesses are calculated using

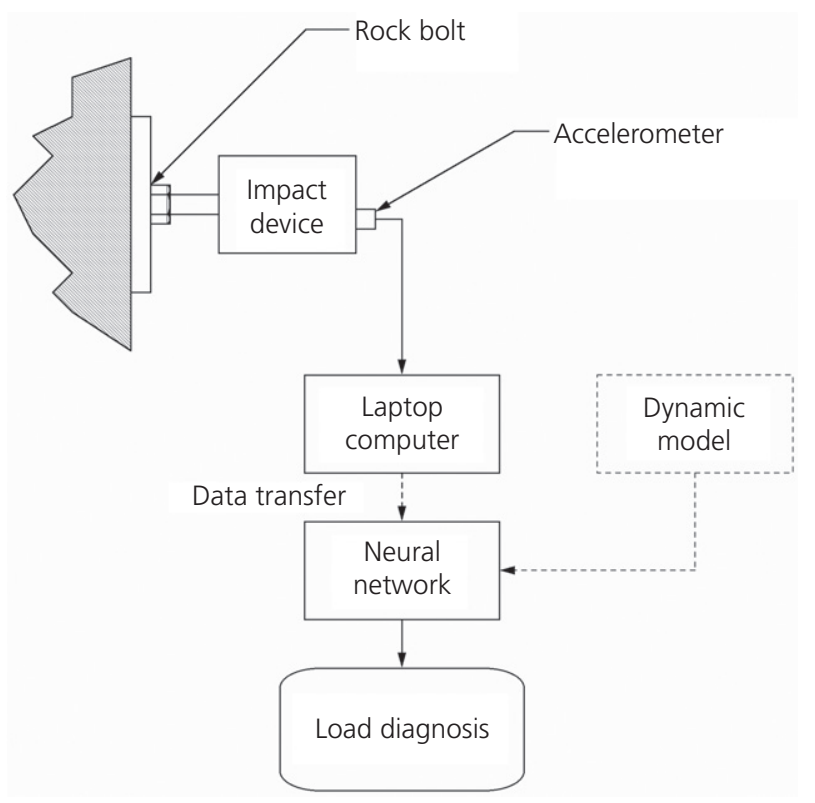

Figure 2. Schematic diagram of the Granit system the plate theory by Young (1989). The damping terms are functions of the mass, stiffness and an experimentally obtained damping coefficient (Ivanović et al., 2002). The anchor head in the model consists of a mass representing the nut and the bearing plate, and a single non-linear stiffness representing the combined stiffness of the bending of the plate and the effects of the interface between the plate and the rock. The stiffness of this interface is defined as $k_{\mathrm{bp}}$. This stiffness, required as an input for the lumped parameter model, is measured on an anchor head test rig through a test procedure reported previously (Ivanović and Neilson, 2008). The results from these tests give the load-displacement curve between the bearing plate and concrete surface in the form of a polynomial equation

\section{1. $F=a x^{3}+b x^{2}+c x+d$}

In the tests, two cycles of increasing and decreasing load were undertaken (Figure 3). Localised crushing of the concrete surface accounts for the distance between the start point and the end point of the first cycle, which results in the nonrecoverable deflection. No additional effective plastic deformation is noticed after the second cycle and this is, therefore, taken for reference in the stiffness computation.

The natural frequencies of the systems are calculated in the model, for different load levels, by an eigenvalue analysis using a local linearisation of the non-linear head stiffness. The equivalent linear stiffness of the head $k_{\mathrm{bp}}$ is calculated for each load level by using the tangent stiffness of that particular load (Figure 3). This is obtained by differentiating the loaddisplacement curve (Equation 2) which gives

2. $k_{\mathrm{bp}}=3 a x^{2}+2 b x+c$

and substituting this in the displacement corresponding to the required load. The model allows the dynamics of the system to be replicated effectively and more computationally efficiently than if the whole system was simulated by means of, for example, finite-element (FE) modelling.

As an initial stage in the investigation, the variations of fundamental frequency were explored by changing the stiffness ratio of the head, $k_{\mathrm{hp}}$, relative to the stiffness of the free length of the steel tendon, $k_{\text {bolt }}$. The aim was to ascertain what range of stiffness ratio of head to bolt is required to provide good load estimation. The results are shown in Figure 4 and are expressed in terms of $r$, the ratio between anchor head stiffness $\left(k_{\mathrm{bp}}\right)$ and the stiffness of the free length of the steel tendon $\left(k_{\text {bolt }}\right)$

3. $r=\frac{k_{\mathrm{bp}}}{k_{\mathrm{bolt}}}$ 


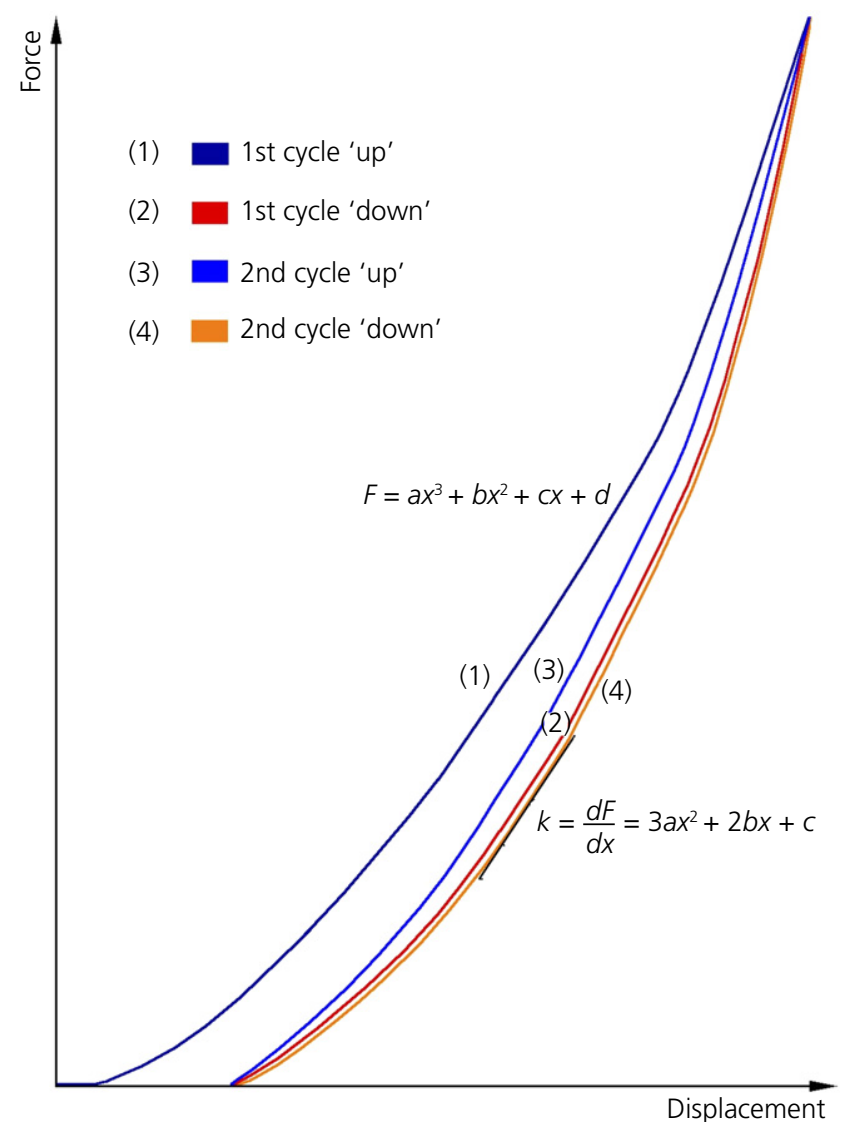

Figure 3. Load-displacement curve of a bearing plate

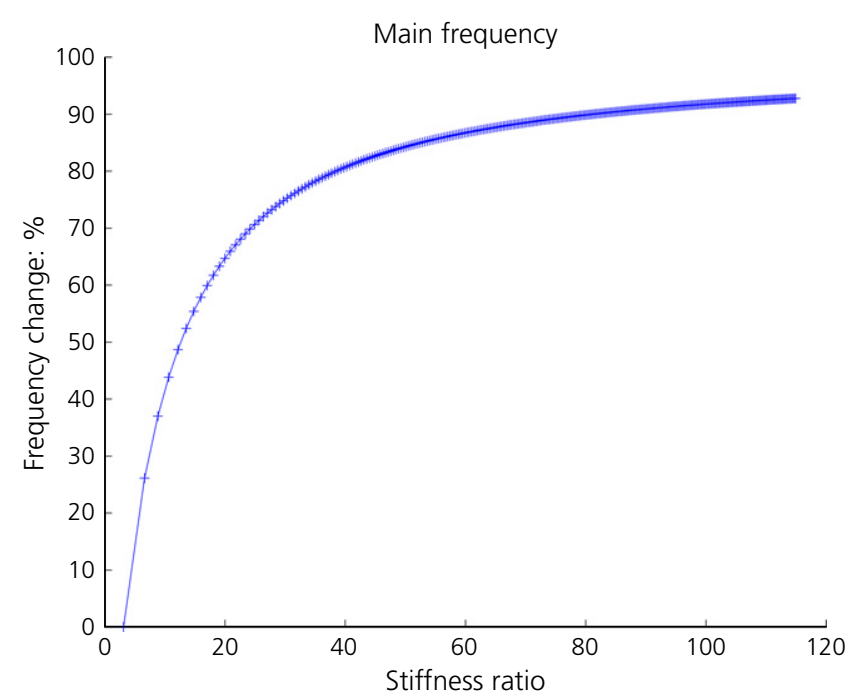

Figure 4. Frequency change with stiffness ratio where $k_{\text {bolt }}=A E / l_{\text {free, }} A$ is the cross-section area of the tendon, $E$ is the Young's modulus of steel and $l_{\text {free }}$ is the free length of the anchorage. The percentage of frequency change is calculated with reference to the frequency of the non-loaded anchorage (Starkey et al., 2003).

The frequencies measured are controlled primarily by the stiffness of the tendon and local (tangent) stiffness of the anchor head at a particular load level (Ivanović et al., 2002). Consequently, the greater the variation in stiffness over the load range, the greater the shift in frequency, and so the load can be estimated more accurately. However, if the head stiffness is initially very large in comparison to that of the tendon, then further increases in stiffness with load have little effect on the frequency, and load estimation becomes inaccurate. From Figure 4 , it can be seen that the frequency changes noticeably for lower stiffness ratios $(r<50)$. For higher stiffness ratios $(r>50)$, the frequency change alters by a very small percentage that is insufficient for effective estimation of the load.

This distinction governs whether estimation of the load is possible or not. It is clear that effective load estimation is restricted only to anchorages with lower stiffness ratios, $r$, and therefore any proposed design needs to provide stiffnesses within the range $r<50$. In addition, it would need a stiffness characteristic that is sufficiently progressive to differentiate loads.

The requirement to have a free length, $l_{\text {free, }}$ to provide a tendon stiffness may appear restrictive, as many rock bolt systems will be designed to be fully grouted, as is the case with mining bolts. However, from studies undertaken in North Parks and other mines and in tunnels it is found that all bolts develop free length either during the initial installation where the top end of the grouted length is not usually completely bonded (Neilson et al., 2004a, 2004b) or in some civil engineering cases where it has been de-bonded by using a tape and then grouted (Rodger et al., 1993).

This paper presents the analysis undertaken to design a bearing plate for a tensioned rock bolt that will optimise the stiffness characteristic so that the dynamic response maximises the effectiveness of the Granit system for load estimation while still providing the support required for the mining and construction industries. The novelty of the design compared with standard bearing plates is in its geometry that provides a prescribed non-linear stiffness characteristic.

\section{Plate design and analysis}

To obtain a response from the Granit system which will indicate a change in load, the specification of a bearing plate for use with a typical mining rock bolt application includes: low levels of plastic deformation, a progressive increase of stiffness with load and a load capacity up to $200 \mathrm{kN}$. 
To produce a design with these required characteristics, a number of FE models with typical bearing plates placed on a concrete surface were modelled and modified incrementally using the Abaqus Standard software package v 6.10 (Abaqus, 2012). It should be noted that Abaqus was used to perform a quasi-static analysis to investigate the flexibility of the bearing plate. The stiffness characteristics of the bearing plate obtained from the FE models were then used in the lumped parameter model to perform full dynamic simulations and monitor frequency shifts. A full non-linear dynamic simulation was not required in Abaqus as the only dynamic load is the impulse applied by the impact device; as this is sufficiently small, the head stiffness is effectively within a linear regime during its application.

The developed FE models simulate direct contact between the bottom surface of the plate and the surface of the concrete (base). The contact was simulated by using a penalty contact method that was based on a Coulomb friction model and the general contact algorithm in Abaqus/Standard. The penalty friction formulation is considered to work well for most static problems, including most metal forming applications, and was, therefore, used in the simulations reported here.

Both friction and frictionless tangential interactions were applied at the interface between the plate and the concrete surface on which it was installed to understand how these influenced the system behaviour. Normal interaction was set as 'hard contact'; this allows no inter-penetration of the parts during contact. For the case of normal friction, a friction coefficient, $\mu=0 \cdot 57$, was chosen for the dry contact between the steel and concrete surfaces, and this was based on values reported by Rabbat and Russell (1985). A friction coefficient, $\mu=0 \cdot 74$, was chosen for dry unlubricated contact between the steel surfaces and this was based on values reported by Grigoriev et al. (1996). A number of plates were generated and analysed to obtain a shape that satisfied both the flexibility and load resistance requirements.

\subsection{Square and circular plates of constant thickness}

A commercially available square plate, commonly used in the mining sector, was analysed as a reference for further design simulations. A three-dimensional (3D) FE model of this bearing plate was generated, with the dimensions: $140 \times 140 \mathrm{~mm}$ and a uniform thickness of $7 \mathrm{~mm}$, and a $35 \mathrm{~mm}$ hole with the material properties of the steel of a Young's modulus of $206 \mathrm{GPa}$ and yielding limit of $600 \mathrm{MPa}$. A rigid square block was created as the support surface by taking into consideration that the initial aim was to characterise the stiffness of the plate while it was loaded, without allowing any deformation of the support surface.
The resulting stress distribution showed that the plate had reached its yielding limit at $56 \mathrm{kN}$ and developed plastic deformation. At $170 \mathrm{kN}$, the plate was found to have deformed plastically almost completely, in particular at the sides and the internal edge. It should be noted that in mining applications, this flattening of the plate is often used to visually identify highly loaded bolts.

A circular plate, of the same primary dimensions and properties, was then modelled to investigate whether it could withstand higher loads than the square plate before plastic deformations occurred. The results show that the stresses were distributed axisymmetrically and the plastic limit was reached at $85 \mathrm{kN}$. However, a high stress concentration was evident around the edges of the inner diameter of the plate, indicating that the plate thickness needed to be increased. Neither design meets the criterion of minimising the plasticity, a requirement for a good design.

\subsection{Optimisation of a plate for Granit response}

To achieve the load resistance combined with progressive stiffness, a number of different geometries were further simulated in Abaqus. Since the flexibility of the plate is important, as is its ability to resist high loads, a series of plates were modelled where the cross-section profile decreased from the interior to the outer edge. The plate in the model was supported by a block fixed at the base; a flat secondary plate was introduced on top of the plate to have an even surface, and a nut was used to apply the load to better replicate actual load conditions. As there are no other restraints, the plate can deform freely in all directions. The concrete part was partitioned to refine the mesh in the area of contact to provide accurate results. The results showed that for this style of plate with a reducing thickness the area of contact between the plate, the surface widens as the load increases. When a larger part of the surface is in contact, the bearing plate becomes stiffer and this, in turn, increases the frequency of the whole system. However, the upper profile of the bearing plate also has an influence on the stiffness of the plate as the thickness of the central part of the plate has a larger influence at higher loads, whereas the peripheral part has greater influence at lower loads. In other words, a decrease of the thickness of the peripheral part gives a decrease in frequencies at lower loads, while an increase of the thickness of the central part increases frequencies at higher loads. From the models tested, it was possible to conclude that the frequency response is more dependent on the profile of the cross-section of the plate than on its diameter. Generally, an increase of the plate diameter results in a decrease in the natural frequency because on the overall, the plate becomes more flexible.

Producing a detailed 3D model is computationally expensive, and therefore a comparison with two-dimensional (2D) 


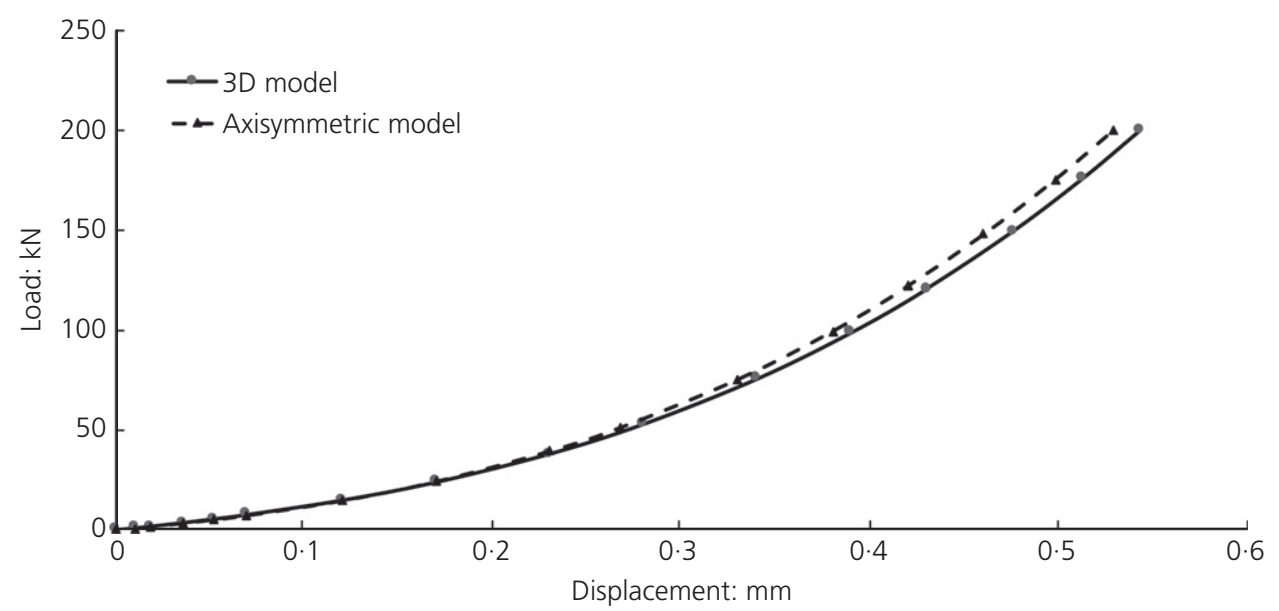

Figure 5. Comparison of load-displacement curves of the 3D and the $2 \mathrm{D}$ axisymmetric models

axisymmetric models was undertaken. The results proved the 2D model to be accurate, while also providing the same response in a much quicker time scale. In addition, an axial symmetric model allowed the production of a much finer mesh, potentially giving better accuracy especially around the contact region. A comparison of the load-displacement curves, shown in Figure 5, indicates that there is no significant difference between the $3 \mathrm{D}$ and the $2 \mathrm{D}$ axisymmetric models. The results proved the models to be equivalent also in terms of the level of displacement, strain and stress, and justified the choice of a 2D axisymmetric model to be used in further analysis.

\section{Cyclic loading analysis}

One of the requirements for the anchor plate was to limit plastic deformation as this could affect its stiffness characteristic (as can be seen in Figure 3). However, it was postulated that if the stresses in the plate exceeded the yielding point during the first loading only, the plastic deformations could be tolerated. A series of loading-unloading cycles were, therefore, simulated to ensure that no further plastic deformation or fatigue occurred within the plate during the load cycles.

Taking all the previous findings into account, the final proposed bearing plate has a $3 \mathrm{~mm}$ thickness at the exterior edge and the thickness increases progressively towards the inner edge. The total height of the plate is $16 \mathrm{~mm}$ and the external diameter measures $140 \mathrm{~mm}$. Figure 6 shows a comparison of the new plate's cross-section profile with that of the standard plate which was used as the initial reference for the study. This profile with the required stiffness characteristics is the novel aspect of the plate.

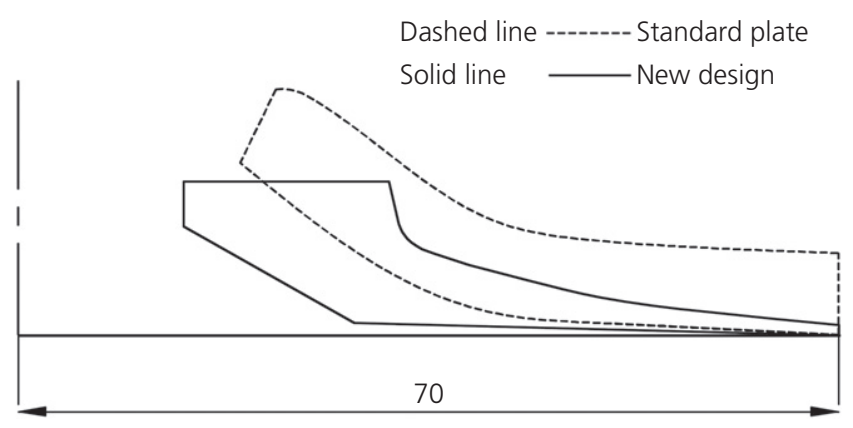

Figure 6. Comparison between the profiles of a commercially available plate and the newly designed bearing plate

To verify that no appreciable deformation of the concrete is present, the supporting block in the FE simulation was then also simulated as a deformable part with elastic resistance of $35 \mathrm{MPa}$ and Young's modulus of $35 \mathrm{GPa}$. During the loading, two surface interactions take place, one at the contact between the plate and the supporting block, and the other at the contact between the nut and the plate; both of the surface interactions are investigated by varying the friction coefficient.

Two models were created to evaluate the importance of the friction at the interfaces. These were

- the steel-concrete interaction used a friction coefficient of $0 \cdot 57$, with the steel-steel contact at 0.74

- a friction coefficient of 0.04 was used at both the contact between the plate and the concrete, and at the contact between the nut and the plate. This value simulates 


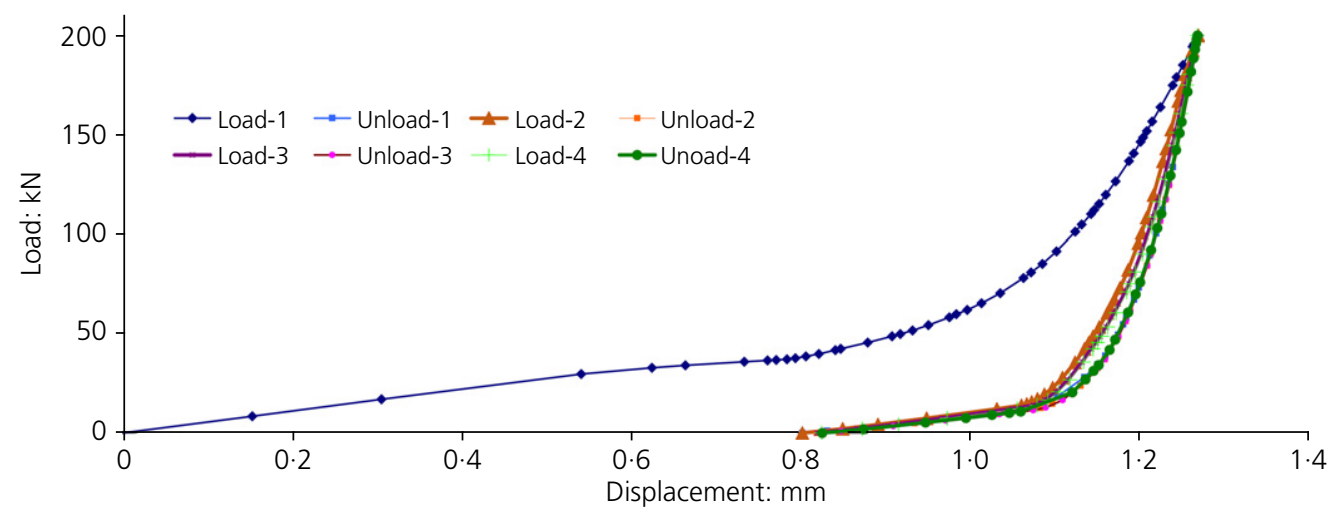

Figure 7. Load-displacement results obtained from the FE analysis of the cyclic loading on the new plate using the friction model

a low friction/lubricated surface - for example, a polytetrafluoroethylene (PTFE)-coated surface which could be used to mitigate any hysteresis resulting from stick/slip at the interfaces.

To evaluate the effect of yielding, four load-unload cycles $(0-200-0 \mathrm{kN})$ were undertaken for each scenario.

\subsection{Friction model, datum case}

\subsubsection{FE results}

The results show that for the datum case, the first load curve is quite different from the subsequent cycles (Figure 7). Plastic deformations spread within the model more consistently than in previous simulations, and this is in accordance with expectations. However, after the first load phase, the stress is always found to be below the steel yielding point. Figure 8(a) shows the plastic strain measured at the point highlighted on the mesh (Figure $8(\mathrm{~b})$ ). There is very little plastic deformation after the first cycle, as can be seen at the points at 7,10 and $12 \mathrm{~s}$ where the load cycles reverse. The contact area progressively increases with increase of load and the bearing plate is completely in contact with the supporting block at the $200 \mathrm{kN}$ load level.

The plate stiffness was obtained from the data and indicated that the stiffness increases by almost 200 times from 0 to $200 \mathrm{kN}$ load. At the $0 \mathrm{kN}$ load, a difference in stiffness between the load phase and the unload phase of $9.6 \%$ was found. At $200 \mathrm{kN}$ load, the difference in stiffness between the loading phase and unloading phase becomes $52 \cdot 6 \%$. This difference between the same load level in the load and unload phase is caused by the friction acting at the bottom of the bearing plate. The surfaces do not slide freely on the horizontal plane, but are restrained partially by friction. This is discussed later.

\subsubsection{Lumped parameter model results}

To observe how the stiffness characteristics of the anchor head influence the overall anchorage frequency response, the lumped parameter model was set up using the material and geometry properties of the anchorage system utilised in previous laboratory tests (Ivanović and Neilson, 2013). This had a free length of $400 \mathrm{~mm}$, fixed length of $2100 \mathrm{~mm}$, protruding length of $100 \mathrm{~mm}$, bolt diameter of $25 \mathrm{~mm}$ and Young's modulus of steel of $E=206 \mathrm{GPa}$. The model parameters are given in Table 1. The plate stiffness characteristics obtained from Abaqus were included in the model and the frequency response of the anchorage was determined for four loading cycles $(0-200 \mathrm{kN})$, as shown in Figure 9.

Figure 9 shows that the overall frequency shift is $>2000 \mathrm{~Hz}$ for the $200 \mathrm{kN}$ load variation. Over the range $0-100 \mathrm{kN}$, the average gradient is $\sim 15 \mathrm{~Hz} / \mathrm{kN}$. In the Granit system, sampling of the data is usually undertaken at $20 \mathrm{kHz}$ with 4000-10 000 collected samples, and this provides a resolution of between 2 and $5 \mathrm{~Hz}$ in the frequency domain. For any change to be detected, it therefore needs to result in a frequency shift $>5 \mathrm{~Hz}$. A shift of $15 \mathrm{~Hz} / \mathrm{kN}$, therefore, provides a very useable sensitivity for load estimation. In a real situation, preloading the plate up to $200 \mathrm{kN}$ prior to using it would have advantages as the plastic deformations would have taken place and a quasi-elastic response would result in subsequent cycles.

A change between the first and the subsequent loading phases can be clearly seen in the figure where, with every loading phase, the difference between each subsequent loading cycle decreases. This is different from the unloading cycles, as all of these seem to be consistent. The frequency corresponding to a load of $200 \mathrm{kN}$ can be seen to be different in the loading cycle and in the unloading cycle. This discontinuity results from 


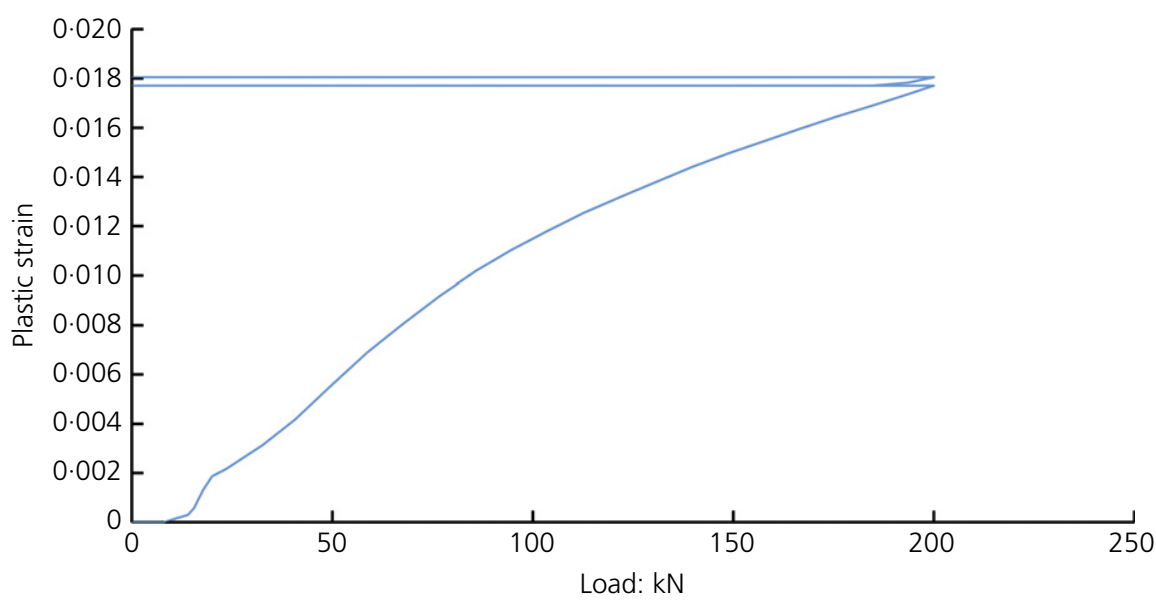

(a)

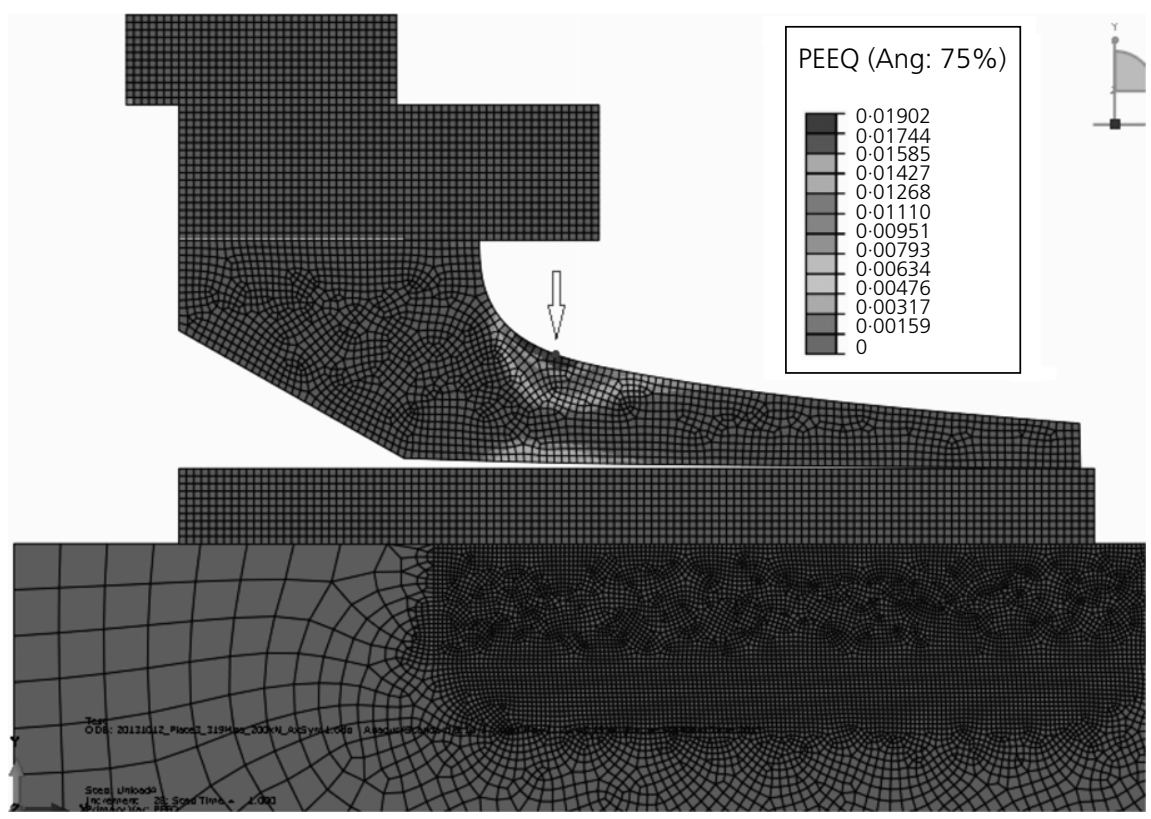

(b)

Figure 8. (a) Plastic strain measurements in the new plate using the friction model and (b) FE analysis showing the point at which the plastic strain obtained in (a) was measured

the differentiation of the load-displacement curve to give the stiffness, and it is possible to explain that this is due to the presence of friction. On loading, the friction resists the movement of the plate as it tries to expand and slide over the supporting surface. On releasing the load, the friction again resists motion but in this case resists the elastic recovery to the original state. From the perspective of estimating load by using the frequency, designing the system so that the loading and unloading curves are as close as possible reduces the chance of errors. To reduce the distance between the two curves, the friction in the system should be minimised. For frictionless contact, all the curves should be the same after the initial plastic deformation of the plate.

\subsection{Friction model, reduced friction}

\subsubsection{FE results}

To investigate this effect and whether the use of a low friction surface at both contact interactions could result in a smaller difference between the different loading cycles, a series of 


\begin{tabular}{|c|c|c|}
\hline Parameter & Description & Value \\
\hline$m_{\mathrm{rb}, \mathrm{pr}}$ & Mass of rock bolt along the protruding length & $0.385 \mathrm{~kg}$ \\
\hline$m_{\mathrm{rb}}$, free & Mass of rock bolt along the free length & $1.541 \mathrm{~kg}$ \\
\hline$m_{\mathrm{rb}, \text { fixed }}$ & Mass of rock bolt along the fixed length & $7 \cdot 321 \mathrm{~kg}$ \\
\hline$m_{\mathrm{rm}, \text { free }}$ & Mass of rock mass along the free length & $56 \cdot 712 \mathrm{~kg}$ \\
\hline$m_{\mathrm{rm}, \text { fixed }}$ & Mass of rock mass along the fixed length & $269 \cdot 384 \mathrm{~kg}$ \\
\hline$k_{\text {rba, }}$ pr & Stiffness of the rock bolt (axial) along the protruding length & $1.016 \mathrm{GN} / \mathrm{m}$ \\
\hline$k_{\text {rba, free }}$ & Stiffness of the rock bolt (axial) along the free length & $25.403 \mathrm{MN} / \mathrm{m}$ \\
\hline$k_{\text {rba, fixed }}$ & Stiffness of the rock bolt (axial) along the fixed length & $53.479 \mathrm{MN} / \mathrm{m}$ \\
\hline$k_{\mathrm{bps}}$ & Stiffness of the bearing plate & $185 \cdot 548 \mathrm{MN} / \mathrm{m}$ \\
\hline$k_{\mathrm{g}}$ & Stiffness of grout & $411.018 \mathrm{GN} / \mathrm{m}$ \\
\hline$k_{\text {rma, free }}$ & Stiffness of the rock mass (axial), along the free length & $6 \cdot 193 \mathrm{GN} / \mathrm{m}$ \\
\hline$k_{\text {rma, fixed }}$ & Stiffness of the rock mass (axial), along the fixed length & $1 \cdot 304 \mathrm{GN} / \mathrm{m}$ \\
\hline$k_{\text {rma, free }}$ & Stiffness of the rock mass (axial), along the free length & $65.016 \mathrm{GN} / \mathrm{m}$ \\
\hline$k_{\text {rma, fixed }}$ & Stiffness of the rock mass (axial), along the fixed length & $308.825 \mathrm{GN} / \mathrm{m}$ \\
\hline Crba, pr & Damping of the rock bolt (axial), along the protruding length & $11.872 \mathrm{kNs} / \mathrm{m}$ \\
\hline$C_{\text {rba, }}$ free & Damping of the rock bolt (axial), along the free length & $11.872 \mathrm{kNs} / \mathrm{m}$ \\
\hline Crba, fixed & Damping of the rock bolt (axial), along the fixed length & $11.872 \mathrm{kNs} / \mathrm{m}$ \\
\hline Cbps & Damping of the bearing plate & $40 \cdot 765 \mathrm{kNs} / \mathrm{m}$ \\
\hline$c_{g}$ & Damping of the grout & $7.632 \mathrm{kNs} / \mathrm{m}$ \\
\hline$C_{\text {rma, free }}$ & Damping of the rock mass (axial), free length & $17.779 \mathrm{kNs} / \mathrm{m}$ \\
\hline$C_{\text {rms, free }}$ & Damping of the rock mass (shear), free length & $57.608 \mathrm{kNs} / \mathrm{m}$ \\
\hline$C_{\text {rms, fixed }}$ & Damping of the rock mass (shear), fixed length & $273.636 \mathrm{kNs} / \mathrm{m}$ \\
\hline
\end{tabular}

Table 1. Model parameters

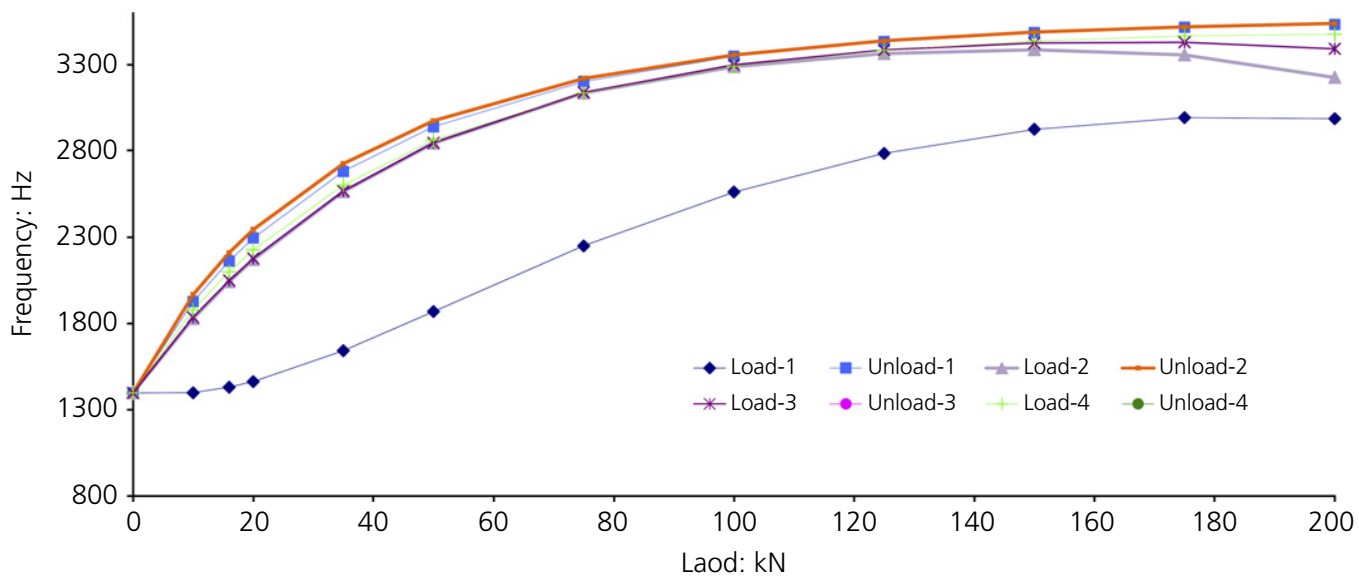

Figure 9. Frequency-load relationship for the friction model:

lumped parameter results

simulations were undertaken with low friction. In this model, PTFE layers were introduced between the plate and the concrete, and between the nut and the plate. This was simulated by reducing the friction coefficient to 0.04 at both contacts.
The resulting loading and unloading curves, shown in Figure 10, indicate that the substantial difference between cycles, found in the cases of higher friction, decreases with the reduction of friction between interfaces. 


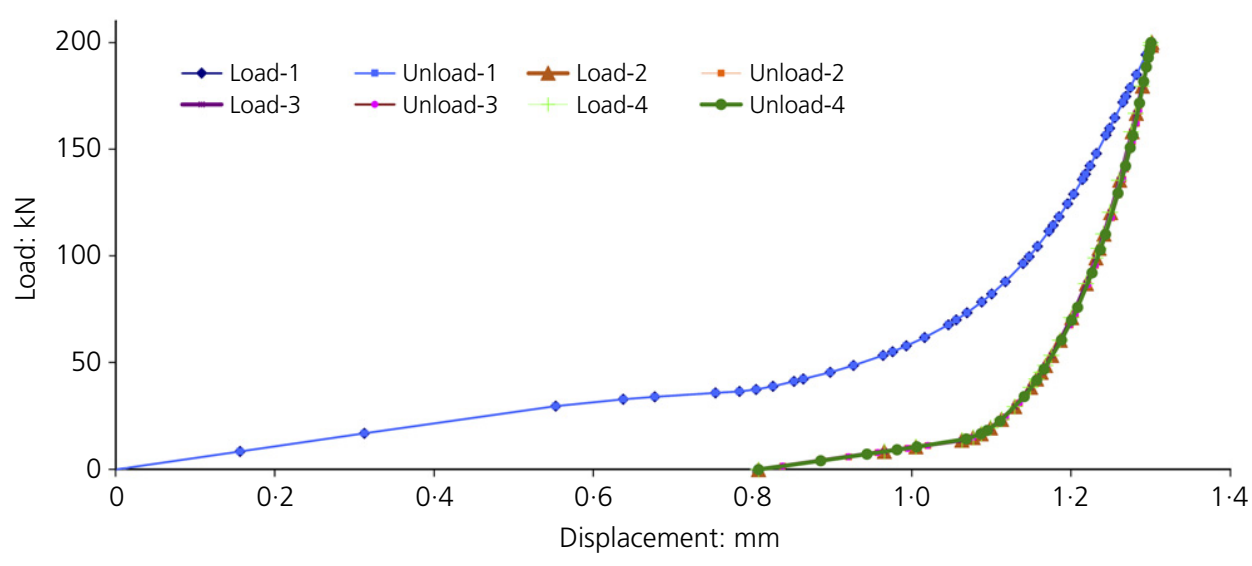

Figure 10. Load-displacement curve for the reduced friction model: FE results

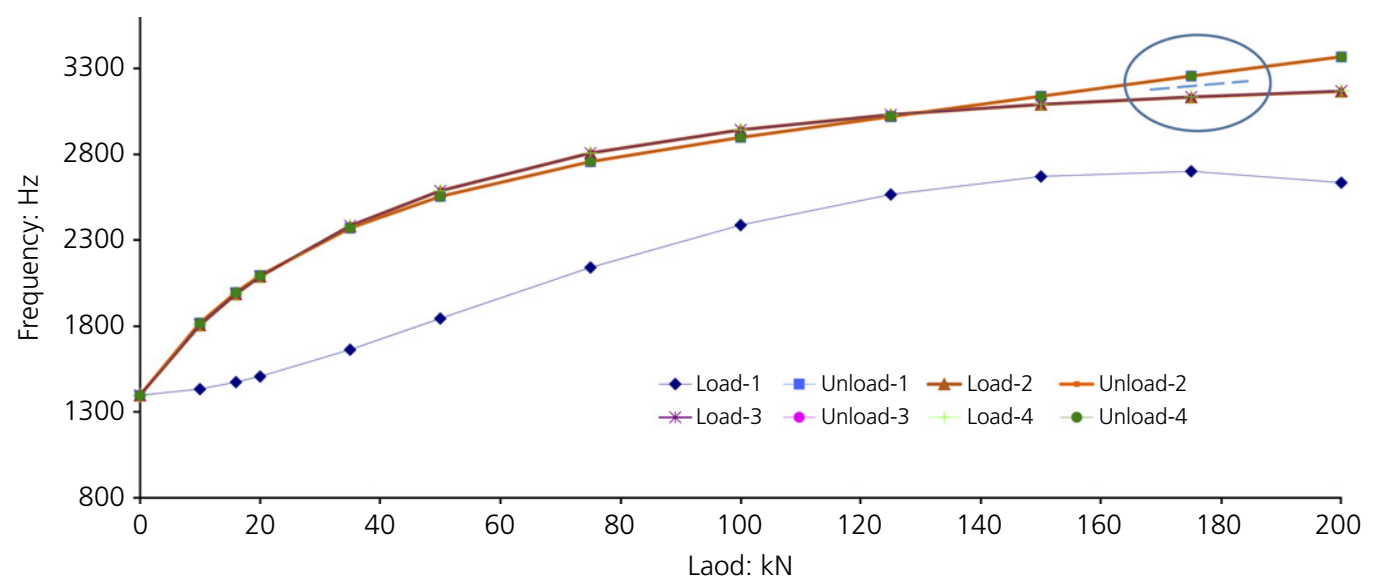

Figure 11. Frequency-load relationship for the reduced friction model: lumped parameter results

\subsubsection{Lumped parameter model results}

The stiffness characteristics of these cycles were again included in the model and the results obtained are shown in Figure 11. As found in the model with higher friction, it is clear that the first cycle trend is still different from the subsequent ones. However, it can be seen that all other loading-unloading curves are superimposed almost perfectly up to $120 \mathrm{kN}$, while with the higher friction (Figure 9) there was a difference of $\sim 120 \mathrm{~Hz}$ at this load. Although there would be less accuracy for load prediction in the range $120-200 \mathrm{kN}$, for typical bolts a load of $180 \mathrm{kN} / 200 \mathrm{kN}$ would be treated as highly stressed and in practice would be anyway followed up with some remedial actions; therefore, an indication that a bolt has exceeded a certain level may be sufficient.

\section{Validation of the plate}

To further confirm the validity of the proposed plate design, a series of static and dynamic physical tests were undertaken and compared with the results from numerical simulations.

\subsection{Static experimental and Abaqus load-displacement testing of the plate}

The plate described was manufactured and tested in the laboratory to measure the actual load-displacement behaviour and validate the simulations. The prototype was manufactured using steel with a yield strength of $319 \mathrm{MPa}$. It was tested using an Instron 8500 testing machine, with the plate placed against a concrete block of $300 \mathrm{~mm}$ diameter, and the vertical 


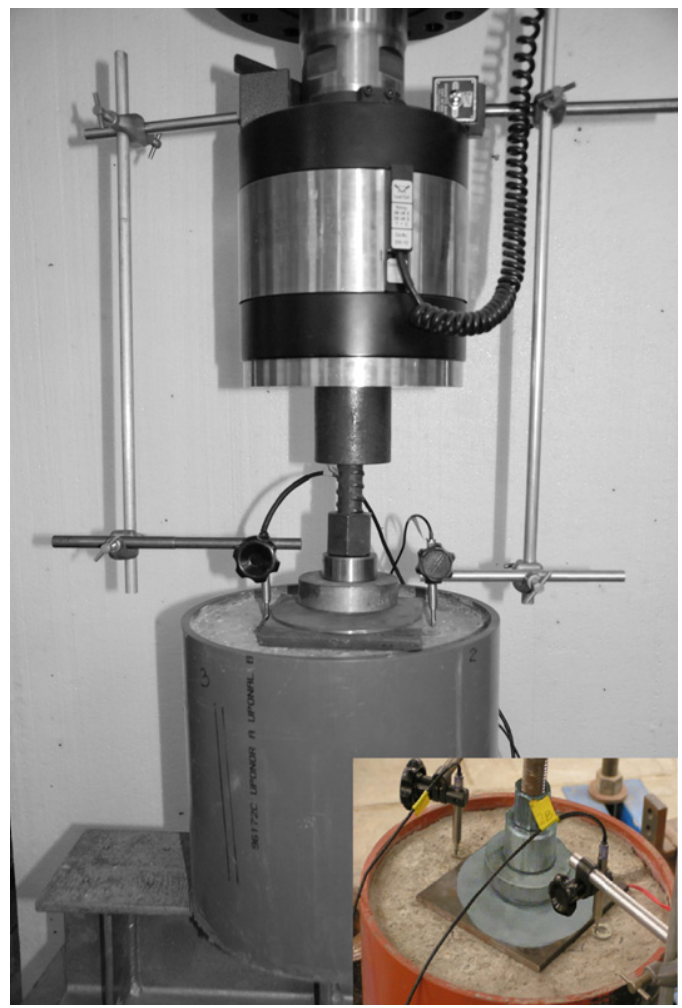

Figure 12. Laboratory test on the bearing plate to measure the actual load-displacement behaviour displacement between the loading head of the Instron and the concrete surface measured using two linear variable differential transformers (RDP D5/200AG) to give the true load-displacement curve (Figure 12). This form of measurement provides the correct stiffness of the plate and interface with no effects from the stiffness of the testing machine or the concrete block. The load was cycled two times, from 0.5 up to $200 \mathrm{kN}$, and then back to $0 \cdot 5 \mathrm{kN}$. For comparison, the same configuration was simulated in Abaqus.

The results show good correlation between the tests and simulations in the $0-200 \mathrm{kN}$ load range. The laboratory tests (Figure 13) showed a clear difference between the first load cycle and consequent cycles as noticed in the FE simulations. The shapes of the curves obtained from the tests and Abaqus simulations appear to be similar, although the initial non-recoverable deformation during the first load cycle is slightly larger in the laboratory experiments compared with the Abaqus simulation. This is thought to be due to the localised crushing of small asperities on the concrete surface in the experiment, a situation which did not occur in the model as the surface is perfectly flat.

\subsection{Dynamic testing and simulation of a test anchorage with the plate}

The plate load-displacement test results were used as input for the lumped parameter model described earlier. The stiffness results from tests were somewhat scattered, and therefore to plot a reasonably well-shaped curve, a logarithmic trend line was generated in the displacement-load graph. This was then differentiated with respect to force to give flexibility. The result was then inverted to give the stiffness as a function of load and

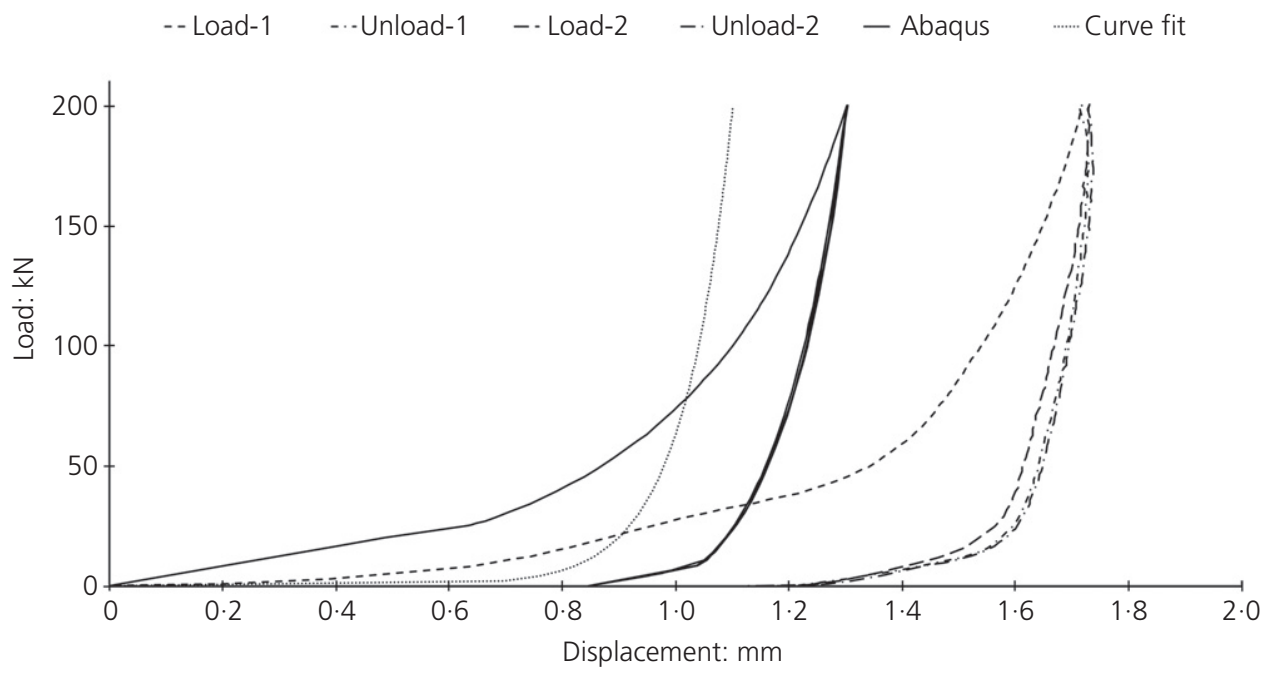

Figure 13. Comparison of the load-displacement curves of the load test and the FE results 


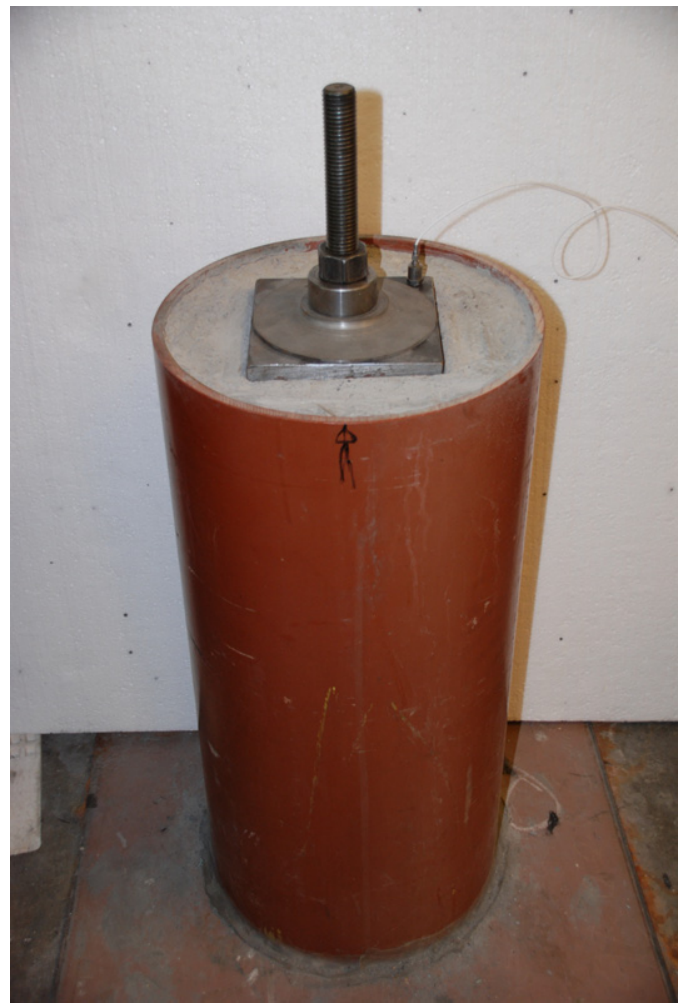

Figure 14. Physical testing on a small laboratory anchorage expressed as

$$
k_{\mathrm{bp}}=11.402 F-8.047
$$

where $F$ is the vertical load (in $\mathrm{N}$ ) and $k_{\mathrm{bp}}$ is the stiffness of the bearing plate (in $\mathrm{N} / \mathrm{m}$ ). This expression shows a linear relationship between stiffness and load. For comparison, the equivalent load-displacement graph for this curve fit is shown in Figure 13 alongside the test curve. The offset along the longitudinal axis does not affect the stiffness calculated from the curve.

To validate the results from the lumped parameter model, physical testing was also undertaken on a small laboratory anchorage shown in Figure 14. This anchorage had protruding free and fixed lengths of 200, 500 and $150 \mathrm{~mm}$, respectively; a bolt diameter of $25 \mathrm{~mm}$; a $28 \mathrm{~mm}$ bore hole and an outer diameter of the concrete of $300 \mathrm{~mm}$. This anchorage was tested using the Granit test which has previously been employed successfully on bolts of this size. The results obtained from the tests are shown along with the corresponding model results in Figure 14. The simulated anchor system has the same geometry and material properties as those used in the laboratory tests and uses the material properties presented in Table 2. The Granit impact device is represented in the model as a mass of $2 \cdot 2 \mathrm{~kg}$ attached to the protruding length, with the bearing plate, the nut and the plate beneath together represented by a mass of $2 \cdot 7 \mathrm{~kg}$.

Figure 15 shows a shift of $\sim 1.3 \mathrm{kHz}$ for the proposed bearing plate over the $0-200 \mathrm{kN}$ load range with the Granit system. When compared with the simulations, using the same

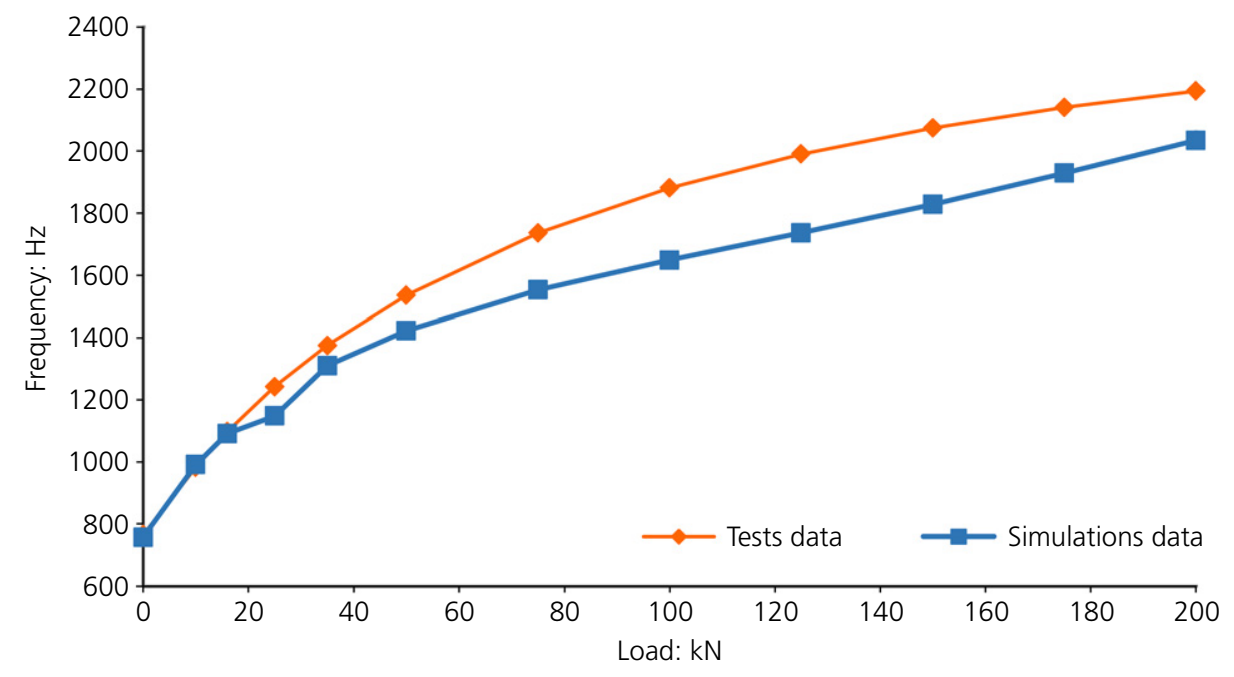

Figure 15. Comparison of frequency-load relationship for the test and simulation results 
Optimisation of ground anchor head for

non-destructive testing

Ivanović, Monese and Neilson

\begin{tabular}{lccc} 
Properties & Resin & Concrete & Steel \\
\hline Density: kg/m & 1825 & 2440 & 7895 \\
Compressive strength: MPa & 80 & $90 \cdot 1$ & - \\
Young's modulus: GPa & 12 & 35 & 207 \\
Poisson's ratio & 0.383 & 0.15 & 0.3
\end{tabular}

Table 2. Material parameters

geometry, it appears that the frequencies from the experimental data are consistently higher than those for the corresponding load levels obtained from numerical simulations. This is unusual as more flexibility would generally be expected in the experimental rig. This suggests that friction may have a larger than expected effect in restricting the movement of the plate in the experiment, resulting in a slightly higher stiffness. However, the overall results indicate that the anchorage, inclusive of the patented newly designed bearing plate (Neilson et al., 2002), is amenable for regular Granit testing and provides a good level of load discrimination.

\section{Conclusions}

This paper presents the results of both experimental and numerical studies of the effect of anchor head stiffness on the vibration response of rock bolt. The aim was to design a bearing plate that could provide prescribed changes in head stiffness with load, thus providing measurable changes in frequency and ultimately allowing for effective non-destructive load estimation. In particular, the aim was to provide a method of modifying those anchorages where the principal frequency does not shift with increasing load and therefore estimation of load is not straightforward. A suitable design, which improves the load estimation capability of the Granit system, has been achieved. The results from the FE simulations and subsequent lumped parameter model show that the introduction of this specifically designed plate can modify the overall anchor head characteristics, allowing the stiffness ratio between the head and the anchor to vary consistently within the workload range. This variation in stiffness ratio leads to a consistent increase of principal frequencies of the anchorage system associated with the increase of load. Care is, however, required to mitigate the effects of friction at the interfaces between the plate and the rock surface as this reduces the reliability of the load estimate. The results obtained from the full-scale experiments indicate that the plate design is a viable solution for load estimation in anchorage systems and could be implemented in practice.

\section{REFERENCES}

Abaqus (2012) Abaqus/CAE User's Manual (Version 6.10).

Dassault Systèmes, Vélizy-Villacoublay, France. See
http://www.sharcnet.ca/Software/Abaqus610/

Documentation/docs/v6.10/books/usb/default.htm (accessed 17/10/2016).

Beard MD and Lowe MJS (2003) Non-destructive testing of rock bolts using guided ultrasonic waves. International Journal of Rock Mechanics and Mining Sciences 40(4): 527-536.

Bigby DN and Arthur J (2001) Improved rockbolting safety worldwide through recent UK instrumentation and testing RTD. In International Symposium on Roofbolting in Mining, RWTH, Aachen, Germany. Wissenschaftsverlag, Mainz, Germany, pp. 463-480.

BSI (1989) BS 8081: 1989: British standard code of practice for ground anchorages. BSI, London, UK.

BSI (1996) BS 7861: Part 1:1996: Strata reinforcement support system components used in coal mines. BSI, London, UK.

Cincilla WA and Tadolini SL (1986) Effects of bearing plates and grout column length on resin-bolt performance. Proceedings of SME Symposium on Engineering Health and Safety in Coal Mining, SME, Littleton, CO, USA, pp. 60-74.

Grigoriev IS, Meilikhov EZ and Radzig AA (1996) Handbook of Physical Quantities. CRC Press, Boca Raton, FL, USA.

Hebblewhite BK and Lu T (2004) Geomechanical behaviour of laminated, weak coal mine roof strata and the implications for a ground reinforcement strategy. International Journal of Rock Mechanics and Mining Sciences 41(1): 147-157.

Ivanović A and Neilson RD (2008) Influence of geometry and material properties on the axial vibration of a rock bolt. International Journal of Rock Mechanics and Mining Sciences 45(6): 941-951.

Ivanović A and Neilson RD (2013) Non-destructive testing of rock bolts for estimating total bolt length. International Journal of Rock Mechanics and Mining Sciences 64(1): 36-43.

Ivanović A, Neilson RD and Rodger AA (2002) Influence of prestress on the dynamic response of ground anchorages. Journal of Geotechnical and Geoenvironmental Engineering, ASCE 128(3): 237-249.

Littlejohn S and Mothersille D (2008) Maintenance and monitoring of anchorages: guidelines. Proceedings of the Institution of Civil Engineers - Geotechnical Engineering 161(2): 93-106, http://dx.doi.org/10.1680/geng.2008.161. 2.93.

Neilson RD, Starkey AJ, Ivanović A, Jackson BH and Ritson AJ (2002) Improved Anchorage Head Assembly. UK patent application PCT/BG2005/003254.

Neilson RD, Rodger AA, Ivanović A et al. (2004a) Rock/cable bolt integrity testing using GRANIT - recent field applications. In 5th International Colloquium on Roofbolting in Mining, Aachen, Germany. Gluckauf, Essen, Germany, pp. 523-528. 
Neilson RD, Ivanović A, Starkey AJ and Rodger AA (2004b) Quality control in rock bolt installation. In 5th International Conference on Quality, Reliability and Maintenance, Oxford, UK, pp. 79-82. Professional Engineering Publishing, Bury St Edmunds, UK.

Neilson RD, Ivanovic A, Starkey AJ and Rodger AA (2007)

Design and dynamic analysis of a pneumatic impulse generating device for the non-destructive testing of ground anchorages. Mechanical Systems and Signal Processing 21(6): 2523-2545.

Rabbat BG and Russell HG (1985) Friction coefficient of steel on concrete or grout. Journal of Structural Engineering, ASCE 111(3): 505-515.

Robert JL and Brachet-Rolland M (1982) Survey of structures by using acoustic emission monitoring. IABSE Reports 39: $33-38$.

Rodger AA, Littlejohn GS, Holland DC and Xu H (1993) Dynamic response of rock bolt systems at Pen y Clip in North Wales. In Options for Tunnelling (Burger H (ed.)). Elsevier, Amsterdam, the Netherlands, Developments in Geotechnical Engineering series, vol. 74, pp. 719-727.

Smelser TW, Dar SD, Pettibone HC and Bolstad DD (1982) Modeling and Field Verification of Roof-Bolt Systems. Society of Mining Engineering, Englewood, CO, USA, pp. 82-121.

Starkey A, Ivanović A, Neilson RD and Rodger AA (2003) Using a lumped parameter dynamic model of a rock bolt to produce training data for a neural network for diagnosis of real data. Meccanica 38(1): 131-142.

Tadolini SC and Ulrich BF (1986) Evaluation of Bearing Plates Installed on Full-Column Resin-Grouted Roof Bolts.

U.S. Bureau of Mines, U.S. Department of the Interior, Washington, DC, USA, RI 9044.

Thurner HF (1979) Non destructive test method for rock bolts. Proceedings of International Congress on Rock Mechanics, Montreux, Switzerland, vol. 3, pp. 254-255.

Villaescusa E, Varden R and Hassell R (2008) Quantifying the performance of resin anchored rock bolts in the Australian underground hard rock mining industry. International Journal of Rock Mechanics and Mining Sciences 45(1): 94-102.

Whitaker A (2001) Critical Assessment of Past Research into Rock Bolt Anchorage Mechanisms. University of New South Wales Mining Research Centre, Sydney, Australia, UMRC Research Report RR3/01.

Wittenberg D and Ruppel U (2000) Quality management for grouted rockbolts. In Proceedings of the 19th International Conference on Ground Control in Mining, Morgantown, $W V$, USA (Peng SS and Mark C (eds)). West Virginia University, Morgantown, VA, USA, pp. 249-254.

Young WC (1989) Roark's Formulas for Stress and Strain, 6th edn. McGraw-Hill, New York, NY, USA.

Zou DHS (2004) Analysis of in situ rock bolt loading status. International Journal of Rock Mechanics and Mining Sciences 41(3): 762-767.

\section{HOW CAN YOU CONTRIBUTE?}

To discuss this paper, please email up to 500 words to the editor at journals@ice.org.uk. Your contribution will be forwarded to the author(s) for a reply and, if considered appropriate by the editorial board, it will be published as discussion in a future issue of the journal.

Proceedings journals rely entirely on contributions from the civil engineering profession (and allied disciplines). Information about how to submit your paper online is available at www.icevirtuallibrary.com/page/authors, where you will also find detailed author guidelines. 